\title{
$-O$ \\ Simple and Complex Gift Exchange in the Laboratory
}

Eline C.M. Van der Heijden*

Jan H.M. Nelissen ${ }^{* *}$

Jan J.M. Potters*

Harrie A.A. Verbon ${ }^{*, * * * *}$

* Department of Economics, and CentER, Tilburg University,

$*$ Faculty of Economics, Erasmus University Rotterdam, and Tinbergen Institute,

$* *$ Department of Social Security Studies, Tilburg University 
Tinbergen Institute

The Tinbergen Institute is the institute for economic research of the Erasmus Universiteit Rotterdam, Universiteit van Amsterdam and

Vrije Universiteit Amsterdam.

Tinbergen I nstitute Amsterdam

Keizersgracht 482

1017 EG Amsterdam

The Netherlands

Tel.: +31.(0)20.5513500

Fax: $\quad+31 .(0) 20.5513555$

Tinbergen Institute Rotterdam

Burg. Oudlaan 50

3062 PA Rotterdam

The Netherlands

Tel.: $\quad+31 .(0) 10.4088900$

Fax: $\quad+31 .(0) 10.4089031$

Most TI discussion papers can be downloaded at

http://www.tinbergen.nl 


\title{
Simple and Complex Gift Exchange in the Laboratory ${ }^{*}$
}

Eline C.M. Van der Heijden ${ }^{*}$, Jan H.M. Nelissen ${ }^{* *}$, Jan J.M. Potters ${ }^{*}$ and Harrie A.A. Verbon ${ }^{*, * * *}$

\author{
*Department of Economics and CentER, Tilburg University \\ ** CentER Applied Research, Tilburg University \\ *** Department of Social Security Studies, Tilburg University
}

\begin{abstract}
We examine an experimental gift exchange game in which the players can improve upon the unique no-gifts equilibrium through cooperative gift giving. The main feature of the study is that there are two different types of gift exchange, which we call simple and complex exchange, respectively. Complex exchange gives higher payoffs than simple exchange but it requires not only mutual trust, like simple exchange, but also a substantial degree of coordination. We examine whether players are able to conclude simple and complex exchanges and how this is affected by the move and matching structure of the game.
\end{abstract}

Keywords: experiments, reciprocity, trust, coordination, gift exchange

JEL-Classification codes: C90, D63, H55

\footnotetext{
* Correspondence: Jan Potters, Tilburg University, Department of Economics, P.O. Box 90153, NL5000 LE Tilburg, the Netherlands, e-mail J.J.M.Potters@kub.nl. Other email-addresses: Eline.vanderHeijden@kub.nl; J.H.M.Nelissen@kub.nl; H.A.A.Verbon@kub.nl. We acknowledge helpful comments from Eric van Damme, Georg Kirchsteiger, two referees and the editor of this journal, and participants of the CentER seminar at Tilburg University and the ESA Meeting in Mannheim. The research was sponsored by the Netherlands Organization for Scientific Research (NWO). The research by Jan Potters is made possible by a fellowship from the Royal Netherlands' Acadamy of Arts and Sciences.
} 


\section{Introduction}

By now there is much experimental evidence that people engage in reciprocal exchange. People are observed to return favors, even in the absence of binding precommitments. They reward kind behavior and punish unkind behavior even in situations in which standard economic theory predicts they would not. For example, in the investment game in Berg et al. (1995) player one chooses how much money to transfer to player two. This money is tripled, and then player two decides how much money to give back to player one. The unique Nash equilibrium is for player two never to give back any money, and, hence, for player one never to give any money in the first place. In the experiments, however, players can be seen to give and return substantial sums of money. This kind of gift exchange has been found in a wide variety of environments and in many institutional settings (for an overview see Fehr and Gächter, 1998). ${ }^{1}$

In all of these experimental studies, the format that the exchange takes is a very basic and simple one. Typically, like in the investment game of Berg et al. (1995), player one first chooses his level of a cooperative act, and then player two immediately reacts with her level of a cooperative act. Not only is such an exchange of a simple format, in the typical experiment the format is also fixed. The enforceability of the exchange relies on the presence of trust and reciprocity, but there are no problems of coordination or arrangement. If an exchange is to take place it is clear what form it will take.

In many real life cases, however, it is not always clear what an exchange should look like. Often, different formats of exchange are available, varying in the level of mutual gains but also in the level of transaction costs. More complex forms of exchange often bring higher mutual gains but also pose more intricate problems of enforcement (North, 1990).

As an illustration one can think of common pool resources, such as irrigation systems, fisheries, community forests, and ground water basins (see Ostrom et al. 1994). These resources are often plagued by both appropriation and maintenance problems. Uncoordinated fishing behavior, for instance, may lead to physical interference of gear, inefficient

\footnotetext{
${ }^{1}$ For instance, even in one-shot interactions the number of reciprocal responses is substantial (Berg et al., 1995, Fehr et al., 1994, Gächter and Falk, 1997), and also the presence of competitive pressures does not eliminate gift exchange (Fehr et al., 1993, 1994). Moreover, reciprocal responses are not eliminated by learning, and they can be observed even when very high stakes are involved (Fehr and Tourgareva, 1995). This evidence has also attracted the interest of theorists, and several models have been advanced which try to account for this kind of behavior (e.g., Fehr and Schmidt, 1997, Güth, 1995, Rabin, 1993, Sugden, 1984).
} 
distribution across spots, increased production costs, and overdepletion of the stock. A variety of formal and informal rules are available to cope with such problems, and these rules differ in terms of complexity and efficiency. For example, fishers may try to coordinate on who fishes when and where, but they also may try to include rules on the amount and type of catch. Although it is not always easy to determine precisely on which dimensions various forms of exchange and arrangement differ, generally the more complex forms are the ones which stretch over a longer time period, which require more coordination, involve more people, and are more costly in case of default (see also North, 1990).

This raises the following important questions. When different forms of exchange are available in principle, which form will be aimed at? When a particular form of exchange is aimed at, how often will it turn out to be enforceable? And, finally, how will the failures and successes of particular exchange forms depend on institutional and environmental conditions? Such questions are important because, as Douglas North puts it, "[t]he evolution of institutions that create a hospitable environment for cooperative solutions to complex exchange provides for economic growth" (1990, p. vii).

In this paper we experimentally study a repeated gift exchange game which allows for reciprocal exchange in both a simple form and a complex form. The unique Nash equilibrium involves no exchange. Simple exchange takes the same form as in the earlier experimental studies. One player gives, the other player returns. Complex exchange brings higher mutual gains than simple exchange, but is also more difficult to enforce. Specifically, it takes at least twice as long to be completed, it requires a certain degree of coordination, and it is more costly if it fails.

A situation that closely matches our game is a quantity-setting duopoly with two symmetric firms operating under increasing returns to scale. In the Nash equilibrium both firms produce their Cournot quantity and earn some profits. If one firm decreases its quantity relative to half the monopoly level, and the other firm reciprocates, then both firms increase their profits. This outcome would be a simple exchange in our terminology. It requires trust and reciprocity to be enforceable, but no coordination is required, and it can be completed within one round of production. There is, however, an outcome available which is even better for the firms. Since there are increasing returns to scale, total profits are maximized if only one firm produces at the monopoly level. If no side payments are possible, then for this to be a profitable deal for both firms, the firms will have to take turns in being the monopolist and being the outsider. Such a cooperative arrangement will be called a complex exchange. It requires at least two rounds of production to be completed. It also requires that the firms 
coordinate who is in and out of the market in each particular round, and if one firm fails to live up to the deal - by entering when it was supposed to stay out - then the cost of default to the other firm is larger than under simple exchange. ${ }^{2}$

In our study we do not merely examine the frequencies of success and failure of simple and complex exchanges, we also relate these frequencies to two environmental variables which have often been found to be important for the enforceability of voluntary cooperation: the move structure and the matching structure. We examine both a simultaneous and a sequential move structure. With a simultaneous move structure, neither player can observe the act chosen by the other player. With a sequential move structure, one player acts first, and the other player can observe this act before he or she acts. We hypothesize that with a sequential move structure it will be easier to accomplish a reciprocal exchange, partly because it is easier to signal trust, and partly because it is easier to coordinate. We also vary the matching structure of the game. In the Partners treatment, players play the game repeatedly against the same opponent. In the Strangers treatment, the players are randomly rematched after each round. We hypothesize that Partners will be able to achieve higher total rates of simple or complex exchange, and, furthermore, that the Partners treatment is a precondition for the occurrence of complex exchange.

We now start by discussing the basic exchange game, along with the definition of the various types of exchange. Section 3 describes the treatment variations that we employed, the corresponding hypotheses, and the experimental procedures. Section 4 analyses the results, and, finally, section 5 concludes.

\section{Game model and definition of types of exchange}

A simple gift exchange game forms the basis for our experiment. The main feature of the game is that gift giving is individually costly, but mutual gift giving is efficient. There are two players, player 1 and player 2, and two periods. In the experiment subjects will be randomly assigned to be player 1 or player 2 . In one period, player 1 receives a high initial endowment of 9 and player 2 receives a low initial endowment of 1 ; in the other period the roles are reversed, player 1 having an endowment of 1 and player 2 an endowment of 9. In the first period player 1 decides

\footnotetext{
${ }^{2}$ In fact, this situation is very similar to the subset of prisoner's dilemma situations in which, like always, mutual cooperation Pareto dominates the unique Nash-equilibrium of mutual defection, but in which the asymmetric outcome, with one player cooperating and the other defecting (complex exchange) gives a higher total payoff than mutual cooperation (simple exchange).
} 
about his gift $T_{1}$ to player 2 ; in the other period player 2 decides about her gift $T_{2}$ to player 1 . Both $\mathrm{T}_{1}$ and $\mathrm{T}_{2}$ are chosen from the set $\{0,1,2, \ldots, 7\}$. If player 1 makes a gift of $\mathrm{T}_{1}$ when he has an endowment of 9 , then his final endowment in that period is 9- $\mathrm{T}_{1}$. If he receives a gift of $\mathrm{T}_{2}$ when he has an endowment of 1 , then his final amount in that period is $1+\mathrm{T}_{2}$. The payoffs to player $i$ are defined as the product of the final endowments in the two periods, that is,

$$
U_{i}=\left(9-T_{i}\right)\left(T_{j}+1\right) \quad \text { for } T_{i}, T_{j} \in\{0,1,2, \ldots, 7\} \text { and } i \neq j \in\{1,2\}
$$

In Table 1 the payoff matrix dictated by eq. (1) is given for both players. The unique Nashequilibrium is for both players to make no gift. Taking the gift $\left(T_{j}\right)$ of the other player as given, it is a best response to play $\mathrm{T}_{\mathrm{i}}=0$. In fact, if no player is informed about the gift of the other player before deciding about his or her own gift, it is even a dominant strategy to play $\mathrm{T}_{\mathrm{i}}=0$ in the oneshot game. In this unique equilibrium both players earn a payoff of $9 \times 1=9$, as can also be deduced from Table 1. We define this unique Nash equilibrium as the 'no exchange':

Definition 1: No exchange (NE) is defined as: $\mathrm{T}_{1}=0 \wedge \mathrm{T}_{2}=0$.

[Table 1 about here]

By playing non-cooperatively the players forego considerable gains from exchange. They can achieve higher payoffs by exchanging gifts. In particular, if players would somehow agree to "give-what-you-get" then gifts would be optimally set at $\mathrm{T}_{1}=\mathrm{T}_{2}=4$. It is easily verified that, subject to the constraint $T_{i}=T_{j}$, the payoff function $U_{i}$ attains its maximum for $T_{i}=T_{j}=4$. In this optimal symmetric outcome both players achieve a payoff of $5 \times 5=25$. But also at lower levels of gift exchange the players achieve substantial improvements over the non-cooperative payoff of 9. For example, at mutual gifts of $T_{1}=T_{2}=2$ (3) they achieve payoffs of $7 \times 3=21(6 \times 4=24)$. Also $\mathrm{T}_{1}=\mathrm{T}_{2}=1$ already gives a proportionally large gain; it results in a payoff of $8 \times 2=16$. In the sequel, we will refer to this form of more or less symmetric gifts as simple gift exchange:

Definition 2: A simple exchange (SE) is defined as: $1 \leq \mathrm{T}_{1}, \mathrm{~T}_{2} \leq 4$.

Simple gift exchange does not achieve the highest sum of the payoffs, however. The maximum value of $U_{1}+U_{2}$ is achieved with $T_{1}=7, T_{2}=0$ ( or $T_{1}=0, T_{2}=7$ ). In that case the sum of the payoffs 
is $74(2+72)$ which is larger than the maximum payoff sum of $50(25+25)$ that can be achieved with simple gift exchange $\left(T_{1}=T_{2}=4\right)$. In fact, Table 1 reveals that whenever $T_{i} \geq 5$ and $T_{j} \leq 3$, the sum of the payoffs is larger than 50. Hence, if one player is very generous and the other one is very thrifty, then the total payoff can be increased above the level that can be achieved with simple gift exchange. Of course, the division of the payoffs over the two players is very uneven with such asymmetric gift giving. Therefore, we cannot expect this outcome to occur in a oneshot play of the game. If players play the game repeatedly in multiple rounds, however - as they will in our experiment - then they may try to alternate between being giver and recipient. For example, if subject $i$ gives a large gift $\left(T_{i}=7, T_{j}=0\right)$ in one round and receives a large gift $\left(T_{i}=0, T_{j}=7\right)$ in the next, then the average payoff can be as large as $0.5 \times(72+2)=37$. We define a complex exchange as follows:

Definition 3: A player realizes a complex exchange (CE) in a pair of rounds (s, s') if $\left(\mathrm{T}_{1} \geq 5, \mathrm{~T}_{2} \leq\right.$ $3)$ in round $\mathrm{s}$, and $\left(\mathrm{T}_{1} \leq 3, \mathrm{~T}_{2} \geq 5\right)$ in round s', with $\mathrm{s} \neq \mathrm{s}$.

It is clear that complex gift exchange poses additional challenges relative to simple exchange. The exchange extends through time, and there is a large variability in the payoff stream. This requires patience and a moderate aversion to risk. More importantly, there is a need to coordinate who is to receive $\left(T_{i} \leq 3\right)$ and who is to give $\left(T_{j} \geq 5\right)$ in a particular round. If both players give a gift of 7 in a round, then both players earn a payoff of $2 \times 8=16$. If both players give a gift of 0 , then both earn a payoff of 9 . Hence, if there is trust and reciprocity but no coordination, then the players are likely to end up with lower payoffs than they could have achieved by means of simple gift exchange.

Note that the above-mentioned definitions do not cover all possible outcomes. The three types of exchanges defined above do not sum to $100 \%$ because some outcomes cannot be attributed to either NE, SE or CE. This holds, in particular, for the combinations $\left(T_{i}=0,1 \leq T_{j} \leq 4\right)$ and $\left(\mathrm{T}_{\mathrm{i}} \geq 5, \mathrm{~T}_{\mathrm{j}} \geq 4\right)$, and rounds with $\left(\mathrm{T}_{\mathrm{i}} \geq 5, \mathrm{~T}_{\mathrm{j}} \leq 3\right)$ which are not followed by a round with $\left(\mathrm{T}_{\mathrm{i}} \leq 5\right.$, $\mathrm{T}_{\mathrm{j}} \geq 3$ ). These outcomes can be considered (coordination) failures. To examine these failures more closely, it would be useful to have a measure of what players are aiming at, their 'attempts', and relate these to their successes. Defining what attempts players are making, is not straightforward, though (even if we abstract from plain errors). For instance, whereas it is reasonable to define a gift of 7 as an attempt to arrive at complex exchange, the intention behind a gift of 0 is less clear. It could aim at arriving at NE, but it could also signal a preference for CE. Another point is that 
both players may have different intentions, e.g., one player may aim at SE, the other at CE. Yet, in spite of these difficulties, we will discuss attempts briefly in the results section. To that end we define an attempt at complex exchange as an outcome with $T_{i} \geq 5$ or $T_{j} \geq 5$, and an attempt at simple exchange as an outcome with $1 \leq \mathrm{T}_{\mathrm{i}} \leq 4$ and $0 \leq \mathrm{T}_{\mathrm{j}} \leq 4$. Hence, we define attempts at the player pairs level rather than the outcome level.

\section{Treatments, hypotheses and experimental procedures}

In our game, players can gain from exchanging gifts. However, though collectively efficient, gifts are individually costly. As the Nash equilibrium implies, each player will be tempted to give nothing. It is likely, however, that this temptation does not only depend on the payoff parameters of the game, but also on other variables such as the possibilities for monitoring and coordination. It is the importance of some of such variables that we want to study. In particular, we manipulate two basic institutional variables, namely, the matching structure (Partners versus Strangers) and the move structure (Simultaneous moves versus Sequential moves), and examine their impact on the degree to which players are able to achieve simple or complex exchanges.

Starting with Andreoni (1988), the comparison of 'strangers' versus 'partners' has been extensively used, particularly in public good games. The main idea is that cooperation is likely to be facilitated when repeated interaction takes place with the same opponents (Partners) rather than with varying opponents (Strangers). ${ }^{3}$ Partners, contrary to Strangers, share both a past and a future. This makes it easier to build up trust and to monitor reciprocity. Partners can react almost directly to each other's actions. With varying opponents (Strangers), it is more tempting to take a free ride on the gifts of the others, and individual defection and non-cooperation are more likely to go unpunished. Strangers will meet other opponents in future rounds, and these new opponents only know their own history. This results in the following hypothesis.

\footnotetext{
${ }^{3}$ The effect of the Partners/Strangers-treatment is still far from settled. Andreoni and Miller (1993) found, for instance, that subjects in a finitely repeated prisoner's dilemma were more cooperative than subjects in a repeated single-shot game. Burlando and Hey (1997), however, conclude that "differences in behavior between partners and strangers sessions might be relatively minor, and be swamped by other differences (...) in our experiment particularly by 'nationality'". They also quote Palfrey and Prisbey (1996) who argue that the difference in behavior between both treatments might be explained from "the amount of noise in the data, with the stranger treatment being the noisier of the two".
} 
HYPOTHESIS 1: The percentage of no exchanges is larger in the Strangers treatment in comparison with the Partners treatment.

Sharing the same information on the history of the experiment also makes coordination easier, which is a prerequisite for complex exchange. Partners know who made a large or small gift in the previous round and can adjust present gifts accordingly. For example, two partners can alternate between giving 7 and giving 0 , irrespective of whether they are player 1 or 2 . Strangers do not share the same historic information, and cannot use this as a cue to coordinate their actions. For instance, a player cannot know whether a stranger gave a gift of 7 or 0 in the previous round. Therefore, we expect a higher percentage of complex exchanges in the Partners treatment than in the Strangers treatment.

The impact of the matching structure on the percentage of simple exchanges is not so clear a priori. Assuming a lower rate of NE for Partners than for Strangers (hypothesis 1), more complex exchanges can go along with both more and less simple exchanges. It is difficult to argue convincingly whether more CE among Partners will go at the expense of SE or at the expense of NE (or at the expense of failures). Therefore, we formulate:

\section{HYPOTHESIS 2:}

(a) The percentage of complex exchanges will be larger for Partners than for Strangers.

(b) The percentage of simple exchange can be either higher or lower for Partners than for Strangers.

In our exchange game, the players move sequentially. Player 1 decides about his gift $\mathrm{T}_{1}$ first; then player 2 decides about her gift $T_{2}$. In one version of the game, which we call the Simultaneous game, player 2 is not informed about $T_{1}$ when she decides about $T_{2}$. The players are in symmetric positions, and essentially play a simultaneous move game. The situation changes substantially if player 2 is informed about $T_{1}$ before she decides on $T_{2}$. In this version of the game, called the Sequential game, the players take asymmetric positions, and the game becomes "truly" sequential.

The move structure is expected to have an impact on the kind and level of gift exchange for two reasons. First, since in the sequential game player 2 is informed about $\mathrm{T}_{1}$, she can react rather than just act. This may strengthen the scope for trust and reciprocity. Several experimental studies suggest that gains from coordination can be realized as a 
consequence of reciprocity (see e.g. Berg et al., 1995; Fehr et al., 1993; Morris et al., 1995). These studies employ a sequential move structure, such that player 2 is able to reward or to punish player 1 . In the simultaneous game, player 2 has to reciprocate an anticipated gift by player 1 (as in the reciprocity definition of Sugden, 1984). In the sequential game, player 2 can reciprocate an observed gift of player 1 (as in the definition of reciprocity by Gouldner, 1960). We expect the reciprocity norm to be triggered more forcefully if a player can actually observe the action of the other player rather than having to anticipate it. Furthermore, if this information has an effect on the strategy of player 2, then it can also be expected to have an effect on player 1 , who has to anticipate this strategy. In the sequential move structure, if player 1 believes that the return gift $T_{2}$ is a positive function of his own gift $T_{1}$ then giving may become more attractive. ${ }^{4}$

A second effect of information (the sequential game) is that it can serve as a coordination device. As we have argued, for complex exchange coordination is crucial. The highest gains from exchange can only be realized if the players are able to coordinate on who is to give the high gift and who is to refrain from giving. Of course, this type of coordination becomes easier if player 1's gift is observed by player 2. In the simultaneous game, even if both players aim at the outcome $\mathrm{T}_{\mathrm{i}}=7, \mathrm{~T}_{\mathrm{j}}=0$, then still they have to coordinate somehow on $(i=1, j=2)$ or $(i=2, j=1)$. This coordination becomes easier if $\mathrm{T}_{1}$ can be observed by player 2 before she chooses $\mathrm{T}_{2}$.

These considerations lead to the following hypothesis.

HYPOTHESIS 3: In comparison with a simultaneous move structure, a sequential move structure results in a higher percentage of both simple and complex exchanges.

\section{Experimental procedure}

In total 16 experimental sessions based on the game described above were run in March 1995 and April 1996. In each session 8 subjects participated. Students from Tilburg University were recruited as subjects. An announcement in the university bulletin solicited participants for a one-

\footnotetext{
${ }^{4}$ Formally, in the simultaneous move structure, each player's strategy $\mathrm{T}_{\mathrm{i}}$ is an element from the set $\{0,1, \ldots, 7\}$. In the sequential move structure player 1 chooses a strategy $\mathrm{T}_{1}$ from $\{0,1, \ldots, 7\}$ and player 2 's strategy is a mapping $\tau_{2}:\{0,1, \ldots, 7\} \rightarrow\{0,1, \ldots, 7\}$, which specifies her action $\mathrm{T}_{2}$ as a function of player 1 's action $T_{1}$. Note that in the sequential move structure player 1 no longer has a dominant strategy of zero gifts. He has to anticipate player 2's reaction to $T_{1}$. Iterated elimination of dominated strategies still leads to the same unique equilibrium outcome of $\mathrm{T}_{1}=\mathrm{T}_{2}=0$, however. See Lensberg and Van der Heijden (1998) for a model that exploits these aspects and tries to disentangle trust, cooperation and reciprocity.
} 
hour decision-making experiment, which would earn them money. No subject had previously participated in any related experiment, and no subject participated more than once. In each session one treatment combination (Partners/Strangers x Simultaneous/Sequential) was run.

Upon arrival, subjects were randomly seated behind computer terminals, which were separated by partitions. Instructions (see Appendix for the Strangers treatment) were distributed and read aloud by the experimenter. After that, subjects were given several minutes to study the instructions more carefully and ask questions (few questions were asked).

Subjects were randomly (re)assigned to be either player 1 or player 2 at the beginning of every round. In the first period, player 1 received a high endowment of 9, player 2 a low endowment of 1 , and player 1 could make a gift $T_{1}$ to player 2 . In the second period, these roles were reversed. ${ }^{5}$ Earnings in each round $\left(\mathrm{U}_{\mathrm{i}}\right)$ were denoted in points and calculated according to equation (1). Subjects were also provided with a table, which gave $U_{i}$ as a function of $T_{i}$ and $T_{j}$. Subjects were informed about $T_{1}$ and $T_{2}$ and their own payoffs in points at the end of a round. ${ }^{6}$ Hence, at that moment subjects knew the size of the gift given to them. Subjects knew that points would be transferred to money earnings at a rate of 1 point $=5$ cents. In addition, they earned a fixed show-up fee of 5 Dutch guilders. ${ }^{7}$ Average earnings amounted to 19.92 Dutch guilders and ranged from 10 to 32.50 Dutch guilders.

After one practice round, subjects played 15 repetitions of the bilateral gift giving game. At the end of round 15, the points earned were accumulated and transferred into money earnings. Then an anonymous questionnaire asked for some background information (gender, age, major, motivation). Finally, subjects were privately paid their earnings in cash.

As said earlier, our experiments differed along two dimensions:

(a) Partners versus Strangers. In the Partners treatment, subjects were randomly matched at the beginning of the first round and these matches remained fixed during all rounds. In the Strangers treatment, players were randomly re-matched every round. Subjects were informed about the matching procedure.

(b) Simultaneous versus Sequential. In the sequential game, player 2 was informed about the gift $T_{1}$ by player 1 before she had to decide on her gift $T_{2}$, whereas in the simultaneous game she was not.

\footnotetext{
${ }^{5}$ In the experiment we used the term transfer (overdracht in Dutch) because it is more neutral than gift, which may have a somewhat positive connotation.

${ }^{6}$ Subjects were asked to type their expectation regarding the transfer that they expected to receive from their opponent in that round of play. Since subjects were not paid to make (accurate) predictions, however, we refrain from making much inferences from the reported expectations.

${ }^{7}$ At the time of the experiments, one Dutch Guilder exchanged for about 0.65 US Dollars.
} 
We had 8 subjects in each session, except for one session in the Partners treatment with sequential move structure in which only 6 subjects showed up. In the Strangers treatments all 8 players interact and, strictly speaking, each session gives only one independent observation. In the Partners treatments the players interact in fixed pairs and therefore each pair generates one independent observation. The characteristics of each treatment combination, their abbreviations and the number of sessions, subjects and independent observations are listed in Table 2.

[Table 2 about here]

\section{Results}

In this section we present the results of our gift exchange experiment. In section 4.1 we will test the hypotheses. Section 4.2 discusses the development of behavior over time and considers the data at the individual level of the subjects.

\subsection{Testing hypotheses}

Before formally testing the hypotheses, formulated in the previous section, we first present an overview of the resulting outcomes. Tables $3 \mathrm{a}$ and $3 \mathrm{~b}$ give the frequency distribution of gifts for the simultaneous and the sequential game, respectively, in the Strangers treatment. Tables $3 \mathrm{c}$ and $3 \mathrm{~d}$ give this same information for the Partners treatment. The resulting percentage of exchanges (NE, SE and $\mathrm{CE}$ ) can be found in the grey parts of the various tables. The percentage of (non-cooperative) no exchanges is shown in the upper left cell $\left(T_{1}=0, T_{2}=0\right)$. The simple exchanges are situated in the light grey rectangular area bounded by $\left(T_{1}=1, T_{2}=1\right)$ and $\left(\mathrm{T}_{1}=4, \mathrm{~T}_{2}=4\right)$. Complex exchanges are included in the upper right grey part and the lower left grey part of the tables. As complex exchanges follow a dynamic definition, not all reported percentages are successful ones, here. For example, an outcome of $(7,0)$ is part of a CE only if it is followed by an outcome of, e.g., $(0,7)$, in a later round.

[Tables 3a-3d about here]

First we have a look at the Strangers data. Table 3a (S-sim) reveals that 33.3\% (100/300) of the outcomes does not involve any gift by either player and leads to NE. Simple exchanges $\left(1 \leq \mathrm{T}_{1}, \mathrm{~T}_{2} \leq 4\right)$ can be seen to occur in $19.7 \%$ (59/300) of the cases. Even some complex 
exchanges can be observed. In 19 cases $(6.3 \%)$ at least one of the two players aims at CE $\left(\mathrm{T}_{\mathrm{i}}>5\right)$, and such a CE is actually realized twice $(0.7 \%)$. Table $3 \mathrm{~b}$ reveals that Strangers playing the sequential game shows a comparable picture. $26.0 \%$ of the outcomes can be classified as NE, $20.0 \%$ as $\mathrm{SE}$ and $3.0 \%$ as CE. Hence, although a large portion of the exchanges can be classified as NE, also a substantial portion of Strangers is able to conclude successful simple exchanges.

Under the Partners treatment the picture is quite different, as can be inferred from Tables $3 \mathrm{c}$ and $3 \mathrm{~d}$. The fraction of no-exchanges is much lower. In the simultaneous game NE occurs in 22 out of 165 observed interactions (13.3\%), and 21 out of 180 cases $(11.7 \%)$ in the sequential game. Furthermore, in the P-sim treatment 24.2\% (40/165) of the interactions refers to SE and this figure is $23.3 \%$ (42/180) for the P-seq treatment. Now, however, a substantial portion of the interactions concerns CE. In P-sim, at least one the players aims at CE $\left(\mathrm{T}_{\mathrm{i}} \geq 5\right)$ in $33.3 \%$ of the cases, and a CE is actually realized in $20.6 \%$ of the interactions. For P-seq, these figures are 39.4\% (attempts at CE) and 20.0\% (successful CE), respectively.

We now proceed by formally testing our three main hypotheses. For that purpose, Table 4 summarizes the classification of the outcomes for the four treatments.

[Table 4 about here]

\section{HYPOTHESIS 1}

This hypothesis predicts a larger percentage of no exchanges in the Strangers treatments than in the Partners treatments. This is clearly supported by the data. In the Strangers treatment about $30 \%$ of the interactions is in line with the Nash equilibrium, whereas this is only about $12 \%$ in the Partners treatment. A one-tailed Mann-Whitney $U$ test results in a significant higher percentage of No Exchange interactions for the Strangers treatment in comparison with the Partners treatment. This holds for the simultaneous game $\left(p=0.003 ; \mathrm{n}_{\mathrm{P}, \mathrm{sim}}=11, \mathrm{n}_{\mathrm{S}, \mathrm{sim}}=5\right)$ as well as the sequential game $\left(p=0.032 ; \mathrm{n}_{\mathrm{P}, \mathrm{seq}}=12, \mathrm{n}_{\mathrm{S}, \mathrm{seq}}=5\right)$.

\section{HYPOTHESIS 2}

Hypothesis 2(a) postulates a higher percentage of successful complex exchanges for the Partners than Strangers. In line with this hypothesis, Table 4 shows that the fraction of CE is much smaller for Strangers ( $0.7 \%$ for S-sim and 3.0\% for S-seq) than for Partners $(20.6 \%$ for P-sim and $20.0 \%$ for P-seq). Somewhat surprisingly, these large average differences do not 
lead to a significant statistical difference. The one-tailed Mann-Whitney $U$ test gives a significance level of $p=0.134$ for the simultaneous game (with $\mathrm{n}_{\mathrm{P}, \mathrm{sim}}=11 \mathrm{n}_{\mathrm{S}, \mathrm{sim}}=5$ ) and $p=0.440$ for the sequential game $\left(\mathrm{n}_{\mathrm{P}, \mathrm{seq}}=12, \mathrm{n}_{\mathrm{S}, \mathrm{seq}}=5\right) .{ }^{8}$ Closer inspection of the data reveals that this insignificance is caused by the large variation across the different Partner pairs. Some are able to conclude up to 10 successful CEs, whereas many pairs are not able to conclude any $\mathrm{CE}$ at all. We will come back to this in the next section. ${ }^{9}$

Hypothesis 2(b) states that no clear effect of the matching structure on the degree of simple exchanges can be predicted on the basis of a priori reasoning. In line with this we find that the percentage of SE hardly differs between Partners and Strangers. It is a bit higher for Partners (about 24\%) than for Strangers (about 20\%) but the difference is small and insignificant $\left(p=1.000\right.$ for the simultaneous game $\left(\mathrm{n}_{\mathrm{P}, \mathrm{sim}}=11, \mathrm{n}_{\mathrm{S}, \mathrm{sim}}=5\right)$ and $p=0.879$ for the sequential game $\left.\left(\mathrm{n}_{\mathrm{P}, \mathrm{seq}}=12, \mathrm{n}_{\mathrm{S}, \mathrm{seq}}=5\right)\right)$. Also combining the data over the two move structures does not lead to a significant difference.

Hence, it appears that the percentages of CE or SE are not significantly different for Strangers and Partners. There is, however, a significant difference in the total percentage of exchanges (i.e., SE+CE). In Table 4 we can see that in S-sim and S-seq the total percentage of successful exchanges is $20.4 \%$ and $23.0 \%$, respectively. For Partners the corresponding figures are $44.8 \%$ (P-sim) and $43.3 \%$ (P-seq). These differences between Strangers and Partners are significant for both the simultaneous game (at $p=0.027$ ) and the sequential game (at $p=0.082$ ).

\section{HYPOTHESIS 3}

Regarding the effect of the move structure we expected the sequential game to be more favorable to positive gift exchange than the simultaneous game. Table 4 indicates, however, that these expectations are not borne out by the data. For Strangers we observe a higher percentage of simple and complex exchanges for the sequential game, but differences are very small. For Partners, even the reverse holds: more simple and complex exchanges in the simultaneous game than in the sequential game. But again differences are very small. A two-

\footnotetext{
${ }^{8}$ Also combining the data for two move structures does not give a significant difference. That is, for all Partners and Strangers data together we find $p=0.343$ for a one-tailed Mann-Whitney test with $\mathrm{n}_{\mathrm{P}, \mathrm{sim}}+\mathrm{n}_{\mathrm{P}, \mathrm{seq}}=23$ and $\mathrm{n}_{\mathrm{S}, \mathrm{sim}}+\mathrm{n}_{\mathrm{S}, \mathrm{seq}}=10$.

${ }^{9}$ Partners can also be seen to aim at CE much more often than Strangers (see Tables 3a-d). Attempts at $\mathrm{CE}$ (i.e., $\mathrm{T}_{1} \geq 5$ or $\mathrm{T}_{2} \geq 5$ ) comprise $33.3 \%$ of the outcomes in P-sim and $39.4 \%$ in P-seq. For Strangers this is only $6.3 \%$ (S-sim) and $6.7 \%$ (S-seq). Moreover, contrary to the CE-successes, these differences in CE-attempts are significant for both P-sim versus $\mathrm{S}$-sim $(p=0.045)$ and for P-seq versus $\mathrm{S}$-seq $(p=0.001)$.
} 
tailed Mann-Whitney $U$ test concludes that the differences are insignificant. For Strangers we find $p=0.841$ for the difference in SE and $p=0.548$ for $\mathrm{CE}\left(\mathrm{n}_{\mathrm{S}, \mathrm{sim}}=5, \mathrm{n}_{\mathrm{S}, \mathrm{seq}}=5\right)$. For Partners the significance levels are $p=0.976$ for $\mathrm{SE}$ and $p=0.740$ for $\mathrm{CE}\left(\mathrm{n}_{\mathrm{P}, \mathrm{sim}}=11, \mathrm{n}_{\mathrm{P}, \mathrm{seq}}=12\right)$. Also combining the observations for Partners and Strangers $\left(n_{S, s i m}+n_{P, s i m}=16\right.$ and $\left.n_{P, s e q}+n_{S, s e q}=17\right)$, or combining all successful exchanges (SE+CE) does not give a significant difference between the Simultaneous and Sequential version of the game. So, we clearly have to refute hypothesis $3 .^{10}$

These results may suggest that the move structure does not have any impact at all. This is not the case, however, as a closer inspection of Tables 3a-3d reveals. Relative to the Simultaneous game, the Sequential game increases gifts by player 1 and decreases gifts by player 2. For Strangers, for example, $\mathrm{T}_{1}=0$ occurs much more frequently in the simultaneous game $(58.3 \%)$ than in the sequential game $(30.3 \%)$, and the reverse holds for player 2, i.e., the frequency of $\mathrm{T}_{2}=0$ is $53.3 \%$ in treatment $\mathrm{S}$-sim and $74.3 \%$ in treatment $\mathrm{S}$-seq. Also, it can be observed that $\mathrm{T}_{1}=3$ or $\mathrm{T}_{1}=4$ occurs much more frequent in $\mathrm{S}$-seq $(42.6 \%)$ than in $\mathrm{S}$-sim (11.3\%). Similar effects can be seen in the Partners treatment, but here the differences are more moderate (see Tables 3c and 3d). For example, in the simultaneous game $40.6 \%$ of players 1 give zero, versus $23.9 \%$ in the sequential game. Hence, for Strangers, and to a lesser extent for Partners too, we find that a sequential move structure puts the first player in a less favorable position. He is induced to be more cooperative and to signal trust, but is often exploited by player 2 who reciprocates to a lesser extent than in the simultaneous game. ${ }^{11}$

At the end of this section we summarize our main findings. In line with Hypothesis 1 , we find a significantly higher percentage of no-exchanges in the Strangers treatment (about $30 \%$ ) than in the Partners treatment (about 12\%). Also, as hypothesized (2a), we find very few complex exchanges among Strangers (2\%), whereas Partners are able to conclude a substantial degree of complex exchanges (20\%). Due to the large variance across Partnerpairs the difference with Strangers is statistically insignificant though. Hence, we may conclude that to achieve complex exchange, it is a necessary but not a sufficient condition that

${ }^{10}$ Although the percentages of successful SE and CE are not different for the sequential and simultaneous game, one might hypothesize that perhaps the sequential game reduces the number of (coordination) failures. Also for this hypothesis, however, there is no support.

${ }^{11}$ Remember that at the beginning of each round, the participants are randomly assigned to be player 1 or player 2 . Hence, in a sense participants alternate between being the exploitee and the exploiter. In a different version of the experiment (which we do not report here), we had participants in fixed roles, that is, being either player 1 or player 2 in all 15 rounds. We found this change in design to have remarkably little effect on the results. In particular, the difference between the gifts of player 1 and player 2 was very similar to the case where they are randomly re-assigned to roles after each round. 
players interact repeatedly with the same opponent. Furthermore, and in line with hypothesis $2 b$, simple exchange is not the exclusive domain of Partners. Successful simple exchanges are concluded between Strangers at about the same rate (20\%) as Partners (24\%).

Contrary to hypothesis 3 , the move structure has virtually no impact on the percentages of successful simple or complex exchanges. Apparently, the trust and coordination required to reach simple or complex exchange are not much facilitated by a sequential move structure. The fact that player 2 gets information about player 1's move in the Sequential game is not completely innocuous, however. In fact, we find that it induces player 1 to make more gifts and player 2 to make smaller gifts, leading to rather uneven gains from gift exchange.

\subsection{Development of exchanges over time and individual level data}

In the previous section, the main hypotheses have been tested on aggregate session data. Aggregate data, however, do not provide any information about the development of play over the rounds. In the present section we investigate whether there are signs of learning over the rounds. In particular, we examine whether the proportions of successful simple and complex exchange show any development over time. Also, we will have a look at the individual level data, and examine the typical choice pattern of those (pairs of) players that seem best able to coordinate on complex exchange.

Figures 1a-1d illustrate the development of successful exchanges over the rounds. In particular, for each of the four treatments, the figures display the percentage of equilibrium exchanges (NE), simple exchanges (SE), and complex exchanges (CE) over the 15 rounds. Basically, these figures are dynamic extensions of Tables 3a-3d. Remember that a complex exchange is defined as a pair of rounds $\left(s, s^{\prime}\right)$ with $\left(T_{1} \geq 5, T_{2} \leq 3\right)$ in round $s$ and $\left(T_{1} \leq 3, T_{2} \geq 5\right.$, in round s'. One complex exchange is then attributed to both round s and round s'. Also remember that the percentages do not sum to 100 , since some outcomes, such as $\left(T_{1}=0, T_{2}=4\right)$ or $\left(\mathrm{T}_{1}=4, \mathrm{~T}_{2}=7\right)$, cannot be attributed to either $\mathrm{NE}, \mathrm{SE}$, or $\mathrm{CE}$.

[Figures 1a-1d about here]

In the figures there are not much signs in any of the treatments that successful coordination on either simple or complex exchange improves over the rounds. For simple 
exchange, we can even observe a weak decline over the rounds. For example, in the Strangers treatment, taking the two move structures (Simultaneous and Sequential) together, the percentage of SE averages 25.0 in rounds $1-5$, drops to 20.0 in rounds $6-10$, and then decreases to 14.5 in rounds 11-15. Similarly, in the Partners treatments the percentage of SE is at an average level of 29.8 in rounds $1-5$, decreases to 23.5 in rounds $6-10$, and then decreases further to an average of 18.1 in the final 5 rounds. Hence, there are no signs that coordination on simple exchange becomes easier or more important over time.

For complex exchange we can restrict attention to the Partners treatments, since it does hardly play a role in the Strangers treatments. Again, however, there are no clear signs that coordination on CE improves over time. In the Simultaneous Partners treatment (Figure 1c), CE reaches its peak in round 12, and in the Sequential Partners treatment (Figure 1d) it is highest in round 7. In fact, in both figures there are some signs of a reversed U-shape for the pattern of CE. Taking the two move structures (Seq. and Sim.) together, CE is at a level of about $15 \%$ in both rounds $1-5$ and rounds $11-15$, whereas it reaches an average of $28.6 \%$ in the middle rounds 6-10. This would suggest that it takes some time to coordinate on $\mathrm{CE}$, but also that it deteriorates rather easily. In any case, there is no indication that coordination on CE improves steadily over time.

Finally, notice that there are clear signs for an end-game effect. The effect is most clear in the Simultaneous Strangers treatment, where the percentages of equilibrium exchanges (i.e., $\mathrm{T}_{1}=\mathrm{T}_{2}=0$ ) increases markedly. But also in the other three treatments we can observe that the percentage of NE increases in the final three rounds. This is in line with much of the available evidence on social dilemma type of experiments (such as prisoners' dilemmas and public goods games), in which it is often observed that the cooperative orientation of subjects decreases towards the end of the experiment.

We have seen that in the aggregate data there are no signs for an increase of successful exchanges as time passes. Hence, for the average player, plain experience or learning - at least in the time span that we examine - does seem to be enough for an improved coordination on complex exchange. This makes one wonder which factors are responsible for those successful complex exchanges that do in fact occur. Therefore, we will now report on a closer examination of the data pattern at the level of the individual player pairs, and see what makes their attempts at complex exchange successful or unsuccessful. Since the main interest is in complex exchange we will focus on the Partners data.

The first notable feature of the individual level data is that the successes of complex exchange are rather concentrated. Three out of a total of 23 pairs of partners are responsible 
for $61 \%(32 / 52)$ of the successful complex exchanges, whereas 12 pairs do not succeed in concluding any successful exchange. The attempts at complex exchange, defined as $\left(\mathrm{T}_{1} \geq 5\right.$ or $\mathrm{T}_{2} \geq 5$ ), are much less concentrated though. The three pairs of players with the largest number of attempts at complex exchange account for only $31.2 \%(39 / 125)$ of the total number of attempts. Furthermore, there are only 3 pairs of players who never make any attempt at complex exchange.

What then distinguishes the successful attempts from the unsuccessful ones? Unsurprisingly perhaps, this is a rather difficult question to answer. Nevertheless, there are some clear suggestions in the data. First, the fraction of rounds with $\mathrm{T}_{\mathrm{i}}=7$ for one of the players rather than $T_{i}=5$ or $T_{i}=6$ is much higher among the successful attempts at complex exchanges than among the unsuccessful ones. In particular, $88.5 \%(46 / 52)$ of the successful complex exchanges involves one of the players choosing 7 , whereas this is only $58.9 \%$ (43/73) for the unsuccessful attempts ( $p<0.001$ with Chi-square test). Choices of 7 are clearly overrepresented in the successful complex exchange attempts. Furthermore, of the three player pairs that succeeded in having 10 or more complex exchanges (see above), two of them have one of the players choosing a 7 already in the very first round. Among the other 20 pairs there is only one with a 7 in the very first round, while four are choosing a 5 or a 6 without any (future) success. Finally, it is noticeable that the patterns of the two most successful pairs are remarkably regular. From round 4 until round 14 they display a perfect pattern of alternation between $(0,7)$ and $(7,0)$. There is only one pair that succeeded in having more than two complex exchanges with a pattern that is different from regular alternation between $(0,7)$ and $(7,0)$. Furthermore, there are only four complex exchanges of the form $(0,7)$ and $(7,0)$, on a total of 30 that are not followed or preceded by another one. Hence, successful complex exchanges tend to follow a regular optimal pattern and they tend to come in streaks.

Of course, these results are rather descriptive and do not provide conclusive statistical evidence on the typical pattern of successful complex exchange. Nevertheless, they seem to suggest that attempts at complex exchange are most likely to be successful when they send the clearest possible signal. A choice of 7 makes a player vulnerable to exploitation but it aims at the highest possible joint payoff. As such it sends the clearest signal about trust, commitment and future intentions. Therefore, it is more likely to be successful than choices of 5 or 6 , which have a flavor of compromise and hesitation and are more likely to be misunderstood. Moreover, it would appear that intentions should be signaled as soon as possible. In the early rounds of the game there still is a clean historical record and signals seem easier to interpret. 
Later in the game signals of trust and commitment (by choosing 7) will be mused with earlier experience and seem to become less effective.

\section{Summary and concluding discussion}

In the present study we have examined a repeated bilateral gift-exchange game. The unique Nash-equilibrium of the game is the zero-gift outcome. Players can improve upon this outcome through mutual gift giving. Like in most previous experimental studies of gift exchange, our game allows for efficiency enhancing gift exchange of a relatively simple format. One player gives and the other player returns. The main innovation of the present study is that it also allows for a more intricate form of gift exchange, whereby the size of the gifts is larger and reciprocity is delayed rather than instantaneous. Complex exchange generates higher average payoffs than simple exchange but is also more difficult to achieve. Like simple exchange, complex exchange requires trust and reciprocity, but in addition it requires some degree of coordination and it is more costly in case of failure.

The purpose of our study was to investigate whether and under what circumstances subjects will (try to) arrive at no exchange, simple exchange or complex exchange. We distinguished two treatment variables. The first treatment variable was related to the matching structure: in the Strangers treatment individuals were randomly rematched after each round, while in the Partners treatment matches remained fixed over the rounds. The second treatment variable was related to the move structure. In the Sequential treatment, the player 2 was informed about the gift of player 1 before deciding about his or her own gift. In the Simultaneous treatment, both players made a decision without knowing the other's decision.

The matching structure appeared to be the more important treatment variable in our experiments. The fraction of equilibrium (i.e., no-exchange) outcomes was significantly higher under the Strangers treatment than under the Partners treatment, and, relatedly, the total number of successful exchanges was significantly higher among Partners. Furthermore, although Strangers were just as well as Partners able to conclude simple exchanges, complex exchanges were almost the exclusive domain of Partners.

The move structure had remarkably little effect on the proportion of outcomes that could be characterized as either no, simple, or complex exchange. Nevertheless, there was one notable impact of the move structure. With sequential moves in the Strangers treatment, gifts by players 1 were significantly higher than gifts by player 2 . The trust by player 1 often was 
not reciprocated by player 2 . Hence, rather than facilitating the coordination on simple or complex exchange, a sequential move structure mainly seemed to affect the strategic positions of the players.

The development of the outcomes over time indicated that coordination on simple or complex exchange did not improve much with experience. To the contrary, a decline of the number of simple exchanges was observed for both Partners and Strangers, a result that is in line with other experiments on social dilemmas. For complex exchange, the development over time was more subtle, showing a reversed U-shape for Partners. Coordination problems seemed to hamper the conclusion of complex exchanges in the early rounds. Then some couples were able to sustain a long period of complex exchanges. But in the final rounds again there was a clear end-effect, with a decay in the number of complex exchanges.

An inspection of the data at the level of the individual player pairs in the Partners treatment, revealed that complex exchange was highly concentrated. Only few pairs were able to conclude a substantial number of complex exchanges. Typically, these pairs sent the clearest signals about trust and commitment to complex exchange and they sent these signals very early in the game. Furthermore, those few pairs that arrived at complex exchanges displayed an almost ideal pattern, with gifts at the efficient level and with perfect alternation between giving and receiving.

Our results indicate (once more) that the non-cooperative equilibrium often is not a very good predictor of behavior in environments that are characterized by substantial gains from cooperation and repeated interaction. At the same time our results underline the difficulty of achieving gains of exchange in an environment which is characterized by multiple focal outcomes. In our study it is not merely the level of exchange (as in most of the experimental literature) but also the type of exchange (simple versus complex) that is an endogenous variable. As a consequence, the problem of developing trust and reciprocity is aggravated by a coordination problem.

Problems of developing trust and coordination are especially evident for complex exchange. Our results indicate that repeated interaction with the same partner is a necessary but by no means sufficient condition. A further necessary condition would seem to be that partners send very clear signals about their intentions and that these signals are understood and returned quickly. Hence, successful complex exchange has a kind of all-or-nothing characteristic. If it comes, it comes quickly and perfectly. Once the interaction has dragged on for some time without much success, signals becomes confounded by earlier signals, and it 
seems to become increasingly difficult to achieve the coordination necessary for complex exchange.

It is interesting to relate our results to the evidence on common pool resources reported in Ostrom et al. (1994). On the basis of both field and experimental data they conclude that the adopted rules to cope with common pool resource problems usually are relatively simple, that is, easy to learn, follow and monitor. They found in their experiments which, in our terminology, allow for simple exchange but not complex exchange - that trust and reciprocity are incrementally built over time, and rules are gradually tested, monitored, and revised. On the other hand, our results indicated that it is very hard to arrive at complex exchange by means of gradual learning and adjustment. In fact, complex exchange may even be hampered by such a period of gradual learning and adjustment. Those players that did arrive at complex exchange typically did so very early on, without much confounding prior history. In line with the suggestion in Ostrom et al. (1994) this hints at the possibility of pathdependency and lock-in. Once players have settled on, or even aimed at a simple but satisfactory kind of arrangement, the complex but more efficient arrangement may become increasingly out of reach (see Kranton, 1996, for a very interesting theoretical model which explicates this possibility).

Several options for further research suggest themselves. First, it could be argued that our experiments did not allow enough time for learning. Although 15 rounds are roughly in line with most of the experimental studies on cooperation and exchange, it cannot be excluded that complex exchange catches up after a longer period of learning. Second, it would be interesting to examine the effect of direct communication. In Ostrom et al. (1994) this option was found to improve the degree of (simple) cooperation much. To what extent it will facilitate coordination on (complex) exchange in the presence of multiple focal outcomes is still an open question. Finally, our results suggest that the mere possibility of both simple and complex exchange hampers the achievement of either. One way to get a clearer view on this would be to run control experiments with two decomposed versions of the present game: one in which the possibility of simple exchange is excluded, and one in which the possibility of complex exchange is excluded. This could indicate whether and to what extent the availability of several exchange types actually worsens the overall outcome. 


\section{Appendix: Instructions (Strangers treatment)}

Introduction (read aloud only) ${ }^{12}$

You are about to participate in an experimental study of decision-making. The experiment will last for about one hour. The instructions of the experiment are simple and if you follow them carefully and make good decisions you may earn a considerable amount of money. All the money you earn will be yours to keep and will be paid to you, privately and confidentially, in cash right after the end of the experiment

\{For the experiment it is of crucial importance to have 8 participants. However, experience shows that often 1 or 2 persons do not show up or do not show up in time. Therefore, we need to have 10 instead of 8 subscriptions. This sometimes has, as now, the consequence that too many participants are present and that 1 or 2 persons cannot participate in this experiment. These persons can still put their name down for one of the following experiments and receive Dfl 10 for any inconvenience. These persons are determined by lot because one or two blank envelopes are added to the box with seating numbers, unless one of you checks in voluntarily not to participate in the experiment and receive Dfl 10 instead.

Before we go on with the instructions, I would like to ask all of you to draw an envelope from this box and open it. The number denotes the terminal you have to be seated. \{If you draw a blank envelope you cannot participate in the experiment and you receive Dfl 10.\}

We will distribute the instructions of the experiment now and read through them together. After that, you will have the opportunity to ask questions. From now on, you are requested not to talk to, or communicate with, any other participant.

Instructions (distributed and read aloud)

\section{Decisions and earnings}

The experiment exists of fifteen separate rounds. In every round, each of you will earn a certain amount of points. At the end of the experiment the points earned in the 15 rounds are added up for each participant separately. Every point earned is worth 5 cent $(\approx \$ 0.028)$ at the end of the experiment. In addition to this, all participants receive a fixed extra amount of Dfl 5. Your total earnings will thus be equal to Dfl 5 plus the number of points earned times 5 cent. Now, we describe how the points earned in each round will be determined.

In each round you will be matched with another participant. Each round will consist of two periods. In every round you have in one period the role of Decider and in the other period the role of Receiver. The earnings of a participant in a round are determined by the final assets of a participant in the period in which he or she is a Decider, and by the final assets of the participant in the period in which he or she is a Receiver. We denote the final assets as Receiver by $\mathrm{E}_{\mathrm{O}}$ and the final assets as Decider by $\mathrm{E}_{\mathrm{B}}$. The earnings in points of a participant in a round are determined by the product of the final assets as Receiver and the final assets as Decider. The earnings of a participant in a round are thus equal to $E_{B} \times E_{O}$ points. Next, we describe how the final assets as Decider $E_{B}$ and the final assets as Receiver $E_{O}$ are determined.

In each round the participants are first randomly matched two by two. After that the computer determines for each couple who will be the Decider in the first period and who will be the Decider in the second period. In the second period the roles are reversed: the Decider in the first period is thus the Receiver in the second period and the Receiver in the first period is the Decider in of the second period. The Receiver starts with an endowment of 1 , whereas the Decider starts with and endowment of 9. The Decider has to decide which part of his or her endowment that he or she wants to transfer to the Receiver. This transfer, which we will denote by $\mathrm{T}$, is 0 at the minimum, and 7 at the maximum. After the Decider has decided about the transfer $\mathrm{T}$ to the Receiver, the final assets of the Receiver are $\mathrm{E}_{\mathrm{O}}=1+\mathrm{T}$, and those of the Decider are $\mathrm{E}_{\mathrm{B}}=9-\mathrm{T}$. After the Decider has decided about her or his transfer to the Receiver, the second period of the round will be started, in which the roles are reversed.

In the second period, the other participant of the couple, who is the Decider now, will have to make a decision. The determination of the final assets of the new Receiver and Decider in this period is similar to the previous period. The Receiver starts with an endowment of 1 and the Decider starts with an endowment of 9. The Decider decides again on the part of her or his endowment that will be transferred to the Receiver. This transfer $\mathrm{T}$ determines the final assets of both participants in the second period: $E_{O}=1+T$ for the Receiver and $E_{B}=9-T$ for the Decider.

As said, your earnings in a round are determined by the product of your final assets $\mathrm{E}_{\mathrm{B}}$ in your role of Decider and the final assets $E_{O}$ in your role of Receiver. Your assets $E_{B}$ are dependent on your transfer to the

\footnotetext{
${ }^{12}$ The text between accolades $(\{\})$ is added when more than 8 participants show up. The text between square brackets ([]) is added in the Sequential move treatment, where the second Decider is informed about the transfer of the first Decider.
} 
Receiver in the period you are Decider and your assets $\mathrm{E}_{\mathrm{O}}$ are dependent on the transfer from the Decider to you in the period you are Receiver. To facilitate the determination of your earnings, you may use the table below.

The table states your earnings in points in a round dependent on the transfer from you to the Receiver when you are Decider and the transfer to you by the Decider when you are Receiver. In this table the rows present the transfer from you as Decider to the Receiver and the columns present the transfer to you as Receiver from the Decider. When you first look for the transfer from you in the row and then go to the right to the column stating the transfer to you, you can read your earnings in points, $\mathrm{E}_{\mathrm{B}} \times \mathrm{E}_{\mathrm{O}}$, for the round. The earnings in money are determined by multiplying the stated amount in points by 5 cents.

\begin{tabular}{|c|c|c|c|c|c|c|c|c|c|}
\hline & & \multicolumn{8}{|c|}{ Transfer to you from the Decider when you are Receiver } \\
\hline & & 0 & 1 & 2 & 3 & 4 & 5 & 6 & 7 \\
\hline Transfer & 0 & 9 & 18 & 27 & 36 & 45 & 54 & 63 & 72 \\
\hline from you & 1 & 8 & 16 & 24 & 32 & 40 & 48 & 56 & 64 \\
\hline to the & 2 & 7 & 14 & 21 & 28 & 35 & 42 & 49 & 56 \\
\hline Receiver & 3 & 6 & 12 & 18 & 24 & 30 & 36 & 42 & 48 \\
\hline when you & 4 & 5 & 10 & 15 & 20 & 25 & 30 & 35 & 40 \\
\hline are & 5 & 4 & 8 & 12 & 16 & 20 & 24 & 28 & 32 \\
\hline \multirow[t]{2}{*}{ Decider } & 6 & 3 & 6 & 9 & 12 & 15 & 18 & 21 & 24 \\
\hline & 7 & 2 & 4 & 6 & 8 & 10 & 12 & 14 & 16 \\
\hline
\end{tabular}

When the two period in a round are over, so when both participants have decided on a transfer, a new round will be started.

\section{Procedure and usage of the computer}

After we have gone through the instructions, first a practice round will be run. After the practice round, the fifteen rounds that determine your earnings for this experiment will be run.

In every round the computer, in a completely random manner, first determines who will be matched to whom. Then the computer determines, again in a random manner, for each couple who will get the role of Receiver and Decider in the first period. On the upper left part of the screen the Decider will see the number of the current round and the message " You are now Decider in the first period". Underneath the Decider will see the question "How much of your endowment do you transfer (0-7)?" The Decider has to type an integer from 0 up to and including 7. The number typed is the transfer $\mathrm{T}$ to the Receiver with whom he has been matched in this round.

Next, the current Decider will be asked the question "How much do you expect to receive?". Here, the Decider types an integer from 0 up to and including 7, dependent on her or his expectation about the transfer she or he expects to receive as Receiver in the next period. This expectation is used by us when analyzing the experiment, but your earnings will be unaffected by it. Besides, the other participants are not informed about your expectations stated.

After all Deciders have made a decision, the first period is over. In the second period the Receivers of the first period are now the Deciders. Every new Decider will see on the screen that in this round he or she is Decider in the second period [and how much he or she has received in the previous period]. Underneath there is the question "How much of your endowment do you transfer (0-7)?. The Decider has to type an integer from 0 up to and including 7. The number typed is the transfer $\mathrm{T}$ to the Receiver with whom he has been matched in this round. When all Deciders of the second period have made a decision all participants will see how much they have received and what their earnings for the rounds are. These earnings are in points and are equal to the product of the final assets as Decider and the final assets as Receiver: $\mathrm{E}_{\mathrm{B}} \times \mathrm{E}_{\mathrm{O}}$. After one has been informed about this, the round is over and a new round will be started.

In the new round, the computer again determines first who will be matched with whom and next for each couple who will be the first Decider. So, you do not know with whom you are matched in a particular round and whether you will be the first or the second Decider.

\section{Summary}

The experiment consists of 15 rounds, and every round consists of 2 periods. In each round the participants are randomly matched two by two by the computer. In each round every participant has in one period the role of 
Decider and in the other period the role of Receiver. When you are Decider your endowment is 9 and your final assets depend on your transfer $T$ to the Receiver: $E_{B}=9-T$. When you are Receiver your endowment is 1 and your final assets depend on the transfer $\mathrm{T}$ by the Decider to you: $\mathrm{E}_{\mathrm{O}}=1+\mathrm{T}$. Your earnings in points in a round are determined by the product of your final assets as Decider and your final assets as Receiver: $E_{B} \times E_{O}$. After the first period of a round is over the new Deciders are informed about the transfer $\mathrm{T}$ which they have received in the first period. After both periods in a round have been finished, everybody is informed about the transfer $\mathrm{T}$ to him or her and his or her earnings in that round.

The matching of the participants and the order in which participants are Decider in the two periods of a round are determined by the computer in a completely random way time after time. You will never be able to know whether you will be the first or the second Decider in a particular rounds, or with whom you are matched in a particular round.

\section{Final remarks}

After the last round, you will first be requested to answer some questions to evaluate the experiment. This questionnaire is anonymous. We can link your answers to your seat number but not to your name. After that, you will be called by your seat number to receive your earnings privately and confidentially. Your earnings are your own business; you do not need to discuss with anyone. It is not allowed to talk to or communicate with other participants during the experiment in either way.

On your table you will find an empty sheet, which you can use to take notes. Additionally, you will find a sheet labelled "REMARKS". On this sheet you can make remarks about the instructions or your decisions.

You get a couple of minutes to go through the instructions and to ask questions. When you want to ask something, please raise your hand. One of us will come to your table to speak to you.

After that we will start the practice round.

Are there any questions? 


\section{References}

Andreoni, J. (1988), Why free ride? Strategies and learning in public goods experiments, Journal of Public Economics, 37, 291-304.

Andreoni, J. and Miller, J.H. (1993), Rational cooperation in the finitely repeated prisoner's dilemma: experimental evidence, Economic Journal, 103, 570-585.

Burlando, R. and Hey, J.D. (1997), Do Anglo-Saxons free ride more?, Journal of Public Economics, 64, 41-60.

Berg, J., Dickhaut, J., and McCabe, K. (1995) "Trust, reciprocity, and social history", Games and Economic Behavior, 10, 122-142.

Fehr, E., Kirchsteiger, G., and Riedl, A. (1993), Does fairness prevent market clearing? An experimental investigation, Quarterly Journal of Economics, 108, 437-459.

Fehr, E., Kirchler, E. Weichbold, A. and Gächter, S. (1994), When social norms overpower competition: Gift exchange in experimental labor markets, Journal of Labor Economics, 16, 324351.

Fehr, E. and Gächter, S. (1998), Reciprocity and economics: The economic implications of Homo Reciprocans, European Economic Review, 42, 845-859.

Fehr, E. and Schmidt, K. (1997), A theory of fairness, competition and cooperation, Discussion paper, University of Zürich.

Fehr, E. and Tourgareva, E. (1995), Do high stakes remove reciprocal fairness - evidence from Russia, Discussion paper, University of Zürich.

Gächter, S. and Falk, A. (1997), Reputation or reciprocity, Working paper, University of Zürich.

Gouldner, A. (1960), The norm of reciprocity: a preliminary statement, American Sociological Review, 25, 161-178.

Güth, W. (1995), An Evolutionary approach to explaining cooperative behavior by reciprocal incentives, International Journal of Game Theory, 24, 323-344.

Kranton, R. (1996), Reciprocal exchange: a self-sustaining system, American Economic Review, $86,830-851$.

Lensberg, T. and Van der Heijden, E.C.M. (1998), A cross-cultural study of reciprocity, trust and altruism in a gift exchange experiment, CentER Discussion paper 9877, CentER, Tilburg University.

Morris, M.W., Sim, D.H., and Girotto, V. (1995), Time of decision, ethical obligation, and causal illusion. In: Kramer, R.M. and Messick, D.M. (eds.), Negotiations as a social process, Sage, Thousands Oaks, 209-239. 
North, D.C. (1990), Institutions, institutional change, and economic performance, Cambridge: Cambridge University Press.

Ostrom, E., Gardner, R., and Walker, J. (1994), Rules, games, and common-pool resources, University of Michigan Press.

Palfrey T.R. and Prisbey, J.E. (1996), Altruism, reputation and noise in linear public goods experiments, Journal of Public Economics, 61, 409-427.

Rabin M. (1993), Incorporating fairness into game theory and economics, American Economic Review, 83, 1281-1302.

Sugden, R. (1984), Reciprocity: the supply of public goods through voluntary contributions, Economic Journal, 94, 72-87. 
Table 1: Pay-off matrix

\begin{tabular}{cc|cccccccc} 
T1 & T2 & 0 & 1 & 2 & 3 & 4 & 5 & 6 & 7 \\
\hline & & & & & & & & & \\
\hline & 9,9 & 18,8 & 27,7 & 36,6 & 45,5 & 54,4 & 63,3 & 72,2 \\
2 & 8,18 & 16,16 & 24,14 & 32,12 & 40,10 & 48,8 & 56,6 & 64,4 \\
3 & 7,27 & 14,24 & 21,21 & 28,18 & 35,15 & 42,12 & 49,9 & 56,6 \\
4 & 6,36 & 12,32 & 18,28 & 24,24 & 30,20 & 36,16 & 42,12 & 48,8 \\
5 & 4,45 & 10,40 & 15,35 & 20,30 & 25,25 & 30,20 & 35,15 & 40,10 \\
6 & 3,54 & 8,48 & 12,42 & 16,36 & 20,30 & 24,24 & 28,18 & 32,12 \\
7 & 2,72 & 4,64 & 6,56 & 8,48 & 10,40 & 12,32 & 14,24 & 16,16
\end{tabular}

a) Between the parentheses the pay-offs are given that result from eq. (1) for player 1 and player 2, respectively. 
Table 2: Overview of the experimental treatments

\begin{tabular}{ccccccc}
\hline \hline $\begin{array}{c}\text { Treatment } \\
\text { abbreviation }\end{array}$ & $\begin{array}{c}\text { matching } \\
\text { structure }\end{array}$ & $\begin{array}{c}\text { move } \\
\text { structure }\end{array}$ & $\begin{array}{c}\# \\
\text { sessions }\end{array}$ & $\begin{array}{c}\text { total \# } \\
\text { subjects }\end{array}$ & $\begin{array}{c}\text { Total \# plays } \\
\text { of the game }\end{array}$ & $\begin{array}{c}\text { \# independent } \\
\text { observations }\end{array}$ \\
\hline S-sim & Strangers & simultaneous & 5 & 40 & 300 & 5 \\
S-seq & Strangers & sequential & 5 & 40 & 300 & 5 \\
P-sim & Partners & simultaneous & 3 & 24 & 180 & 12 \\
P-seq & Partners & sequential & 3 & 22 & 165 & 11 \\
\hline \hline
\end{tabular}


Table 3a: Frequency table for S-sim (in \% and total numbers)

\begin{tabular}{|c|c|c|c|c|c|c|c|c|c|}
\hline $\begin{array}{ll} & \mathrm{T} 2 \\
\mathrm{~T} 1 & \end{array}$ & 0 & 1 & 2 & 3 & 4 & 5 & 6 & 7 & $\begin{array}{l}\text { total } \\
\% \mathrm{~N}\end{array}$ \\
\hline 0 & 33.3 & 10.7 & 7.3 & 3.7 & 1.3 & 0 & 0 & 2.0 & 58.3175 \\
\hline 1 & 6.7 & 2.3 & 2.3 & 1.7 & 0.7 & 0 & 0 & 0 & 13.741 \\
\hline 2 & 5.3 & 1.3 & 3.0 & 2.0 & 1.0 & 0 & 0 & 0 & $12.7 \quad 38$ \\
\hline 3 & 4.0 & 1.0 & 3.0 & 1.0 & 0 & 0 & 0 & 0 & $\begin{array}{ll}9.0 & 27\end{array}$ \\
\hline 4 & 1.7 & 0 & 0.3 & 0 & 0 & 0 & 0 & 0.3 & 2.3 \\
\hline 5 & 1.7 & 0.3 & 0 & 0.3 & 0 & 0 & 0 & 0 & 2.3 \\
\hline 6 & 0 & 0 & 0 & 0 & 0 & 0 & 0 & 0 & 0 \\
\hline 7 & 0.7 & 1.0 & 0 & 0 & 0 & 0 & 0 & 0 & 1.7 \\
\hline total $(\%)$ & 53.3 & 16.7 & 16.0 & 8.7 & 3.0 & 0 & 0 & 2.3 & 100 \\
\hline$(\mathrm{N})$ & 160 & 50 & 48 & 26 & 9 & 0 & 0 & 7 & 300 \\
\hline
\end{tabular}

Table 3b: Frequency table for S-seq (in \% and total numbers)

\begin{tabular}{|c|c|c|c|c|c|c|c|c|c|c|}
\hline $\begin{array}{ll} & \mathrm{T} 2 \\
\mathrm{~T} 1 & \end{array}$ & 0 & 1 & 2 & 3 & 4 & 5 & 6 & 7 & \multicolumn{2}{|c|}{ total } \\
\hline 0 & 26.0 & 0 & 0.7 & 0.3 & 1.0 & 0 & 0 & 2.3 & 30.3 & 91 \\
\hline 1 & 6.3 & 1.0 & 0.3 & 0 & 0 & 0 & 0 & 0.3 & 8.0 & 24 \\
\hline 2 & 11.7 & 2.3 & 1.0 & 0 & 0.3 & 0 & 0 & 0 & 15.3 & 46 \\
\hline 3 & 14.0 & 1.0 & 2.3 & 4.7 & 0 & 0 & 0 & 0.3 & 22.3 & 67 \\
\hline 4 & 13.3 & 2.3 & 1.3 & 1.3 & 2.0 & 0 & 0 & 0 & 20.3 & 61 \\
\hline 5 & 0.7 & 0.7 & 0 & 0 & 0 & 0 & 0 & 0 & 1.3 & 4 \\
\hline 6 & 0 & 0 & 0 & 0 & 0 & 0 & 0 & 0 & 0 & 0 \\
\hline 7 & 2.3 & 0 & 0 & 0 & 0 & 0 & 0 & 0 & 2.3 & 7 \\
\hline total $(\%)$ & 74.3 & 7.3 & 5.7 & 6.3 & 3.3 & 0 & 0 & 3.0 & 100 & \\
\hline $\mathrm{N}$ & 223 & 22 & 17 & 19 & 10 & 0 & 0 & 9 & 300 & \\
\hline
\end{tabular}


Table 3c: Frequency table for P-sim (in \% and total numbers)

\begin{tabular}{|c|c|c|c|c|c|c|c|c|c|}
\hline $\begin{array}{l}\mathrm{T} 2 \\
\mathrm{~T} 1\end{array}$ & 0 & 1 & 2 & 3 & 4 & 5 & 6 & 7 & $\begin{array}{l}\text { Total } \\
\% \quad \mathrm{~N}\end{array}$ \\
\hline 0 & 13.3 & 1.8 & 1.2 & 4.8 & 6.7 & 1.2 & 0 & 12.1 & $40.6 \quad 68$ \\
\hline 1 & 2.4 & 2.4 & 1.8 & 0 & 1.8 & 0 & 0 & 0 & 8.5 \\
\hline 2 & 3.0 & 1.2 & 0.6 & 1.8 & 0.6 & 1.2 & 0 & 1.2 & 9.7 \\
\hline 3 & 5.5 & 0.6 & 1.8 & 0.6 & 1.2 & 0 & 0 & 0.6 & 10.317 \\
\hline 4 & 3.6 & 0 & 0.6 & 2.4 & 6.7 & 0.6 & 0.6 & 1.2 & 15.826 \\
\hline 5 & 1.8 & 0 & 0.6 & 0.6 & 0 & 0.6 & 0 & 0 & 3.6 \\
\hline 6 & 0.6 & 0 & 0 & 0 & 0.6 & 0 & 0 & 0 & 1.2 \\
\hline 7 & 7.3 & 0.6 & 0 & 0 & 1.8 & 0 & 0 & 0 & $9.7 \quad 16$ \\
\hline Total (\%) & 37.6 & 6.7 & 6.7 & 10.3 & 19.4 & 3.6 & 0.6 & 15.2 & 100 \\
\hline $\mathrm{N}$ & 62 & 11 & 11 & 17 & 32 & 6 & 1 & 25 & 165 \\
\hline
\end{tabular}

Table 3d: Frequency table for P-seq (in \% and total numbers)

\begin{tabular}{|c|c|c|c|c|c|c|c|c|c|c|}
\hline $\mathrm{T} 2$ & 0 & 1 & 2 & 3 & 4 & 5 & 6 & 7 & \multicolumn{2}{|c|}{ Total } \\
\hline $\mathrm{T} 1$ & & & & & & & & & & $\mathrm{~N}$ \\
\hline 0 & 11.7 & 0 & 0 & 0 & 0.6 & 0.6 & 0 & 11.1 & 23.9 & 43 \\
\hline 1 & 5.0 & 2.8 & 0 & 1.1 & 0 & 0 & 0.6 & 2.2 & 11.7 & 21 \\
\hline 2 & 1.7 & 0.6 & 1.7 & 0 & 0 & 0 & 0 & 0 & 3.9 & 7 \\
\hline 3 & 4.4 & 0.6 & 0 & 0.6 & 0 & 0 & 0.6 & 0.6 & 6.7 & 12 \\
\hline 4 & 13.9 & 1.1 & 0.6 & 1.7 & 12.8 & 1.7 & 0 & 2.8 & 34.4 & 62 \\
\hline 5 & 2.2 & 0.6 & 0 & 0 & 0.6 & 1.1 & 0 & 0 & 4.4 & 8 \\
\hline 6 & 1.1 & 1.1 & 0 & 0.6 & 1.1 & 0 & 0.6 & 0.6 & 5.0 & 9 \\
\hline 7 & 6.7 & 0.6 & 0.6 & 0.6 & 1.1 & 0 & 0.6 & 0 & 10.0 & 18 \\
\hline Total (\%) & 46.7 & 7.2 & 2.8 & 4.4 & 16.1 & 3.3 & 2.2 & 17.2 & 100 & \\
\hline $\mathrm{N}$ & 84 & 13 & 5 & 8 & 29 & 6 & 4 & 31 & 180 & \\
\hline
\end{tabular}


Table 4: Classification of outcomes

\begin{tabular}{lrrrc}
\hline \hline & \multicolumn{2}{c}{ Strangers } & \multicolumn{2}{c}{ Partners } \\
& Sim & Seq & Sim & Seq \\
\hline No Exchange & 33.3 & 26.0 & 13.3 & 11.7 \\
Simple Exchange & 19.7 & 20.0 & 24.2 & 23.3 \\
Complex Exchange & 0.7 & 3.0 & 20.6 & 20.0 \\
Other & 47.3 & 51.0 & 41.9 & 45.0 \\
\hline \hline
\end{tabular}


Figure 1a: Successful exchanges in S-sim

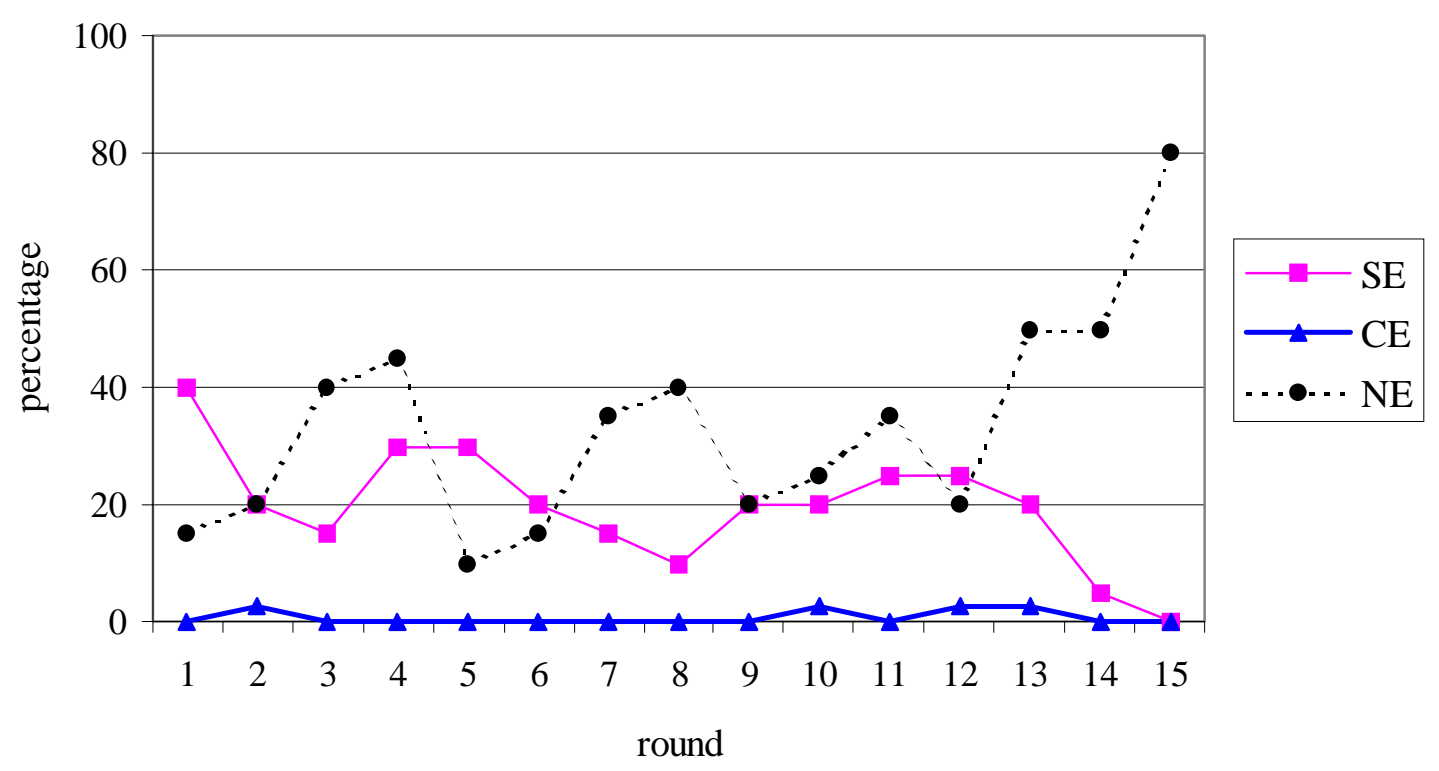

Figure 1b: Successful exchanges in S-seq

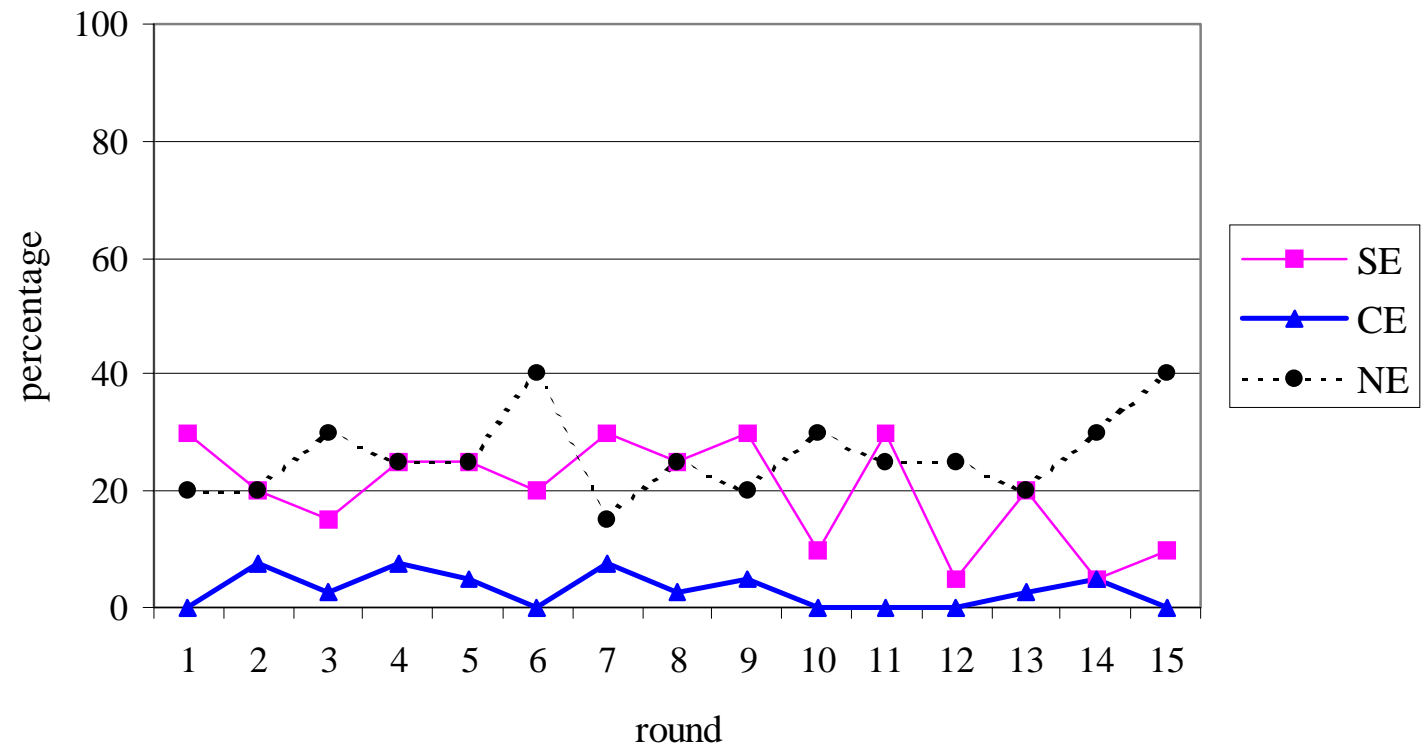


Figure 1c: Successful exchanges in P-sim

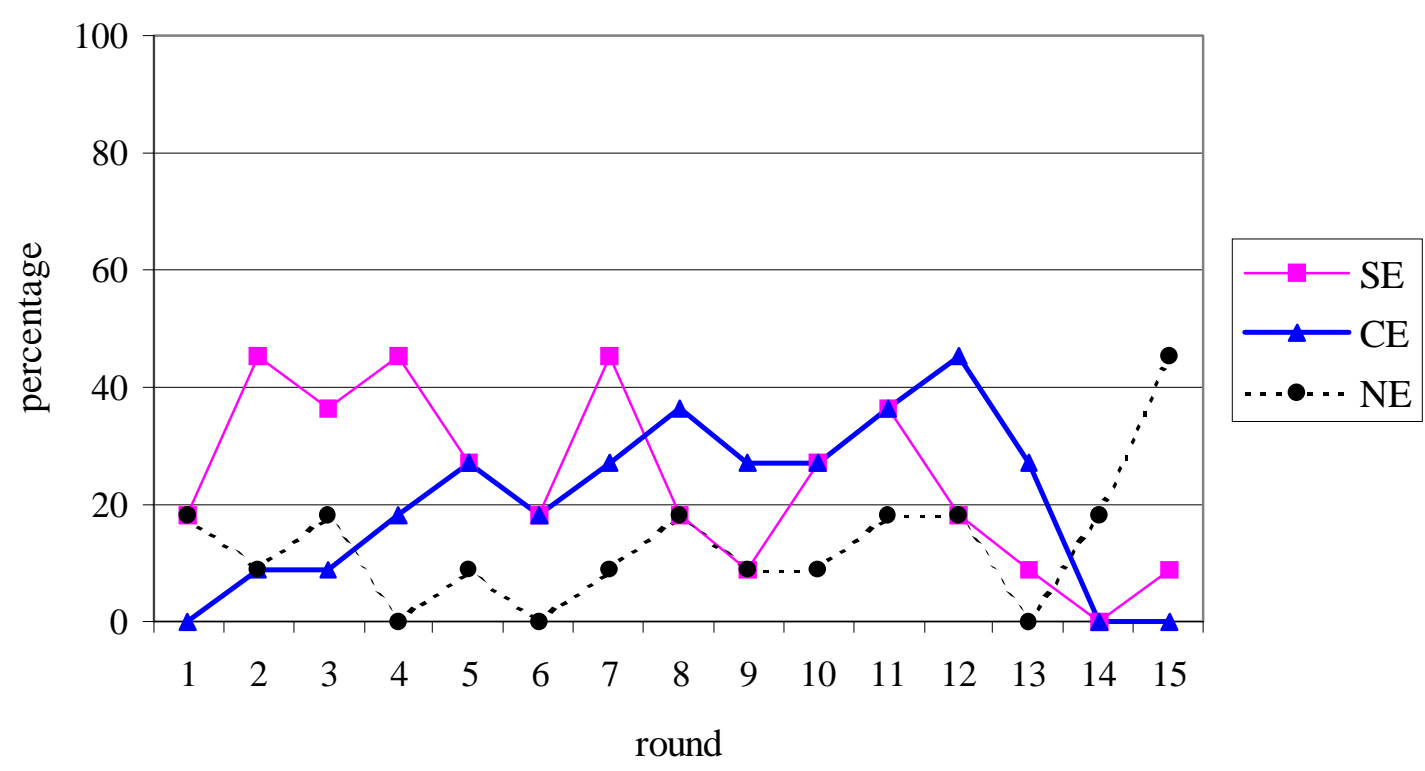

Figure 1d: Successful exchanges in P-seq

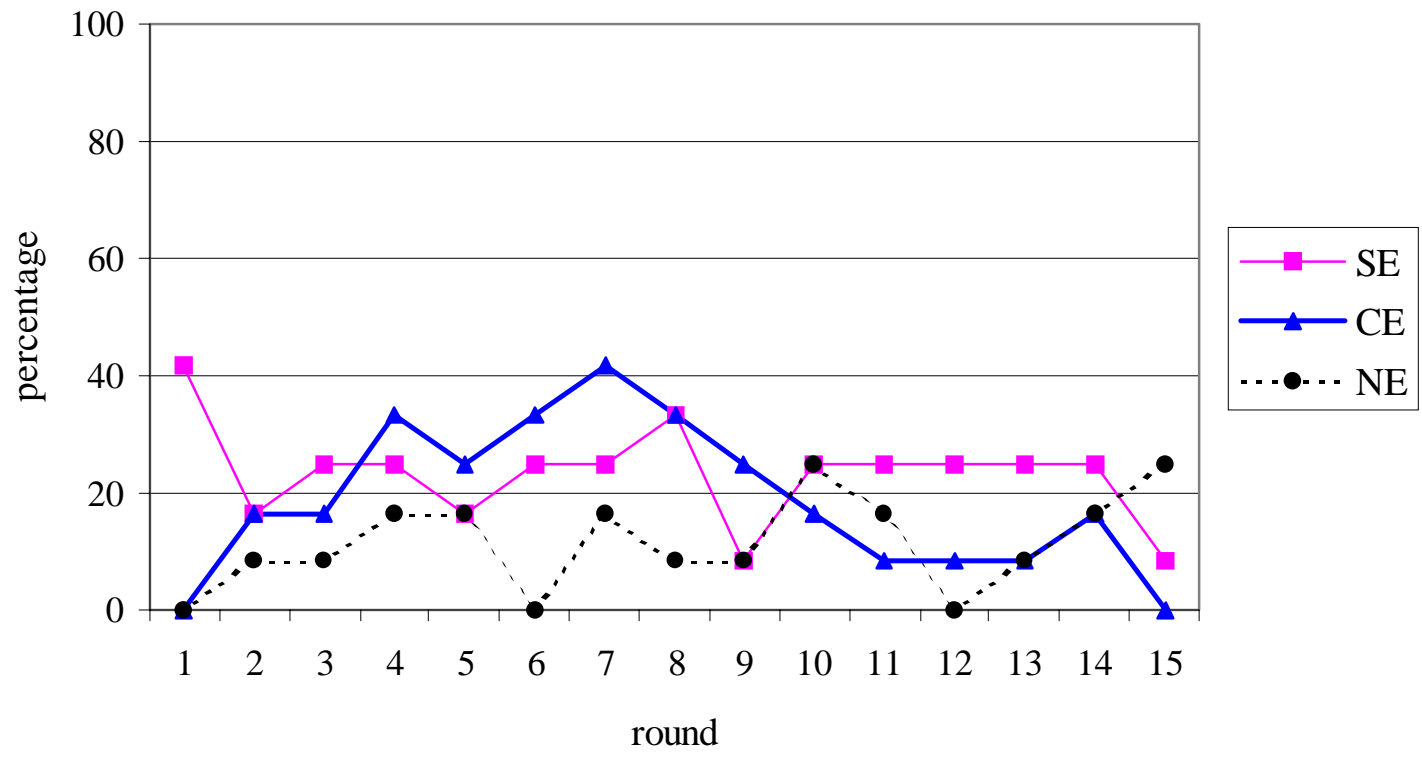

